\title{
Development of Therapeutic Flour and Prepare Standardized Recipe
}

\author{
Shikha Singh ${ }^{1}$, Neetu Singh ${ }^{2}$ \\ ${ }^{1}$ Student, School for Home Sciences, Babasaheb Bhimrao Ambedker University (A Central University), Vidya Vihar, Rae Bareli Road \\ Lucknow-226025, U.P., India
}

${ }^{2}$ Assistant Professor, School for Home Sciences, Babasaheb Bhimrao Ambedker University (A Central University), Vidya Vihar, Rae Bareli Road Lucknow-226025, U.P., India

\begin{abstract}
Therapeutic flour is developed by the mixing of rice bran, chickpea peel and whole wheat flour in different ratio(s) and better results obtained in the ratio(s) of rice bran, chickpea peel and whole wheat flour in 10:10:80 in the development of therapeutic flour and prepare recipes by using therapeutic flour and test characteristics supported by the hedonic scale. One major products were developed using different composite flour i.e. therapeutic flour chilla, (rice bran+chickpea peel+ wheat flour). Developed product was evaluated on various parameters: sensory evaluation \& nutritional analysis. Sensory evaluation of prepared product was carried out using 9 point hedonic scale.
\end{abstract}

Keywords: Therapeutic flour, rice bran, chickpea peel, whole wheat flour

\section{Introduction}

Survey of literature reveals that rice bran, for us various health benefits due to content of antioxidants vitamin A, vitamin E, B vitamins, and essential fatty acids. Rice bran's antioxidants work through different processes to result in positive effects on the biological system. Rice bran is a highly nutritious compound as it is rich source of oryzanols, tocopherols, tocotrienols, phytosterols, and dietary fibers. Chickpea peel is the high protein content, making it an ideal option for vegetarians who want to ensure they have proper nutrient intake full of protein, fiber and iron, and makes a healthy and colorful addition to any meal. Beneficial for Diabetic Management, Blood sugar management, \& soon.

Whole wheat flour is rich in catalytic elements, minerals salts, Calcium, Magnesium, Potassium, Zinc, Iodine, Copper, Vitamin B and Vitamin E. it can help control blood sugar, lower, obesity.LDL or "bad" cholesterol, and reduce colon cancer risk. In the era of increasing diseases among people, foods are required for better nutritional management. While considering the nutritional management staple foods play an important role in our day to day life. Now a days fortified flours and blended flours are available in the market. But demand of supply needed more search to fulfill the requirement of people the present study is a noble steps to meet out this problem and also provide better nutritional management or for curing health hazards.

\section{Material \& Method}

The present study was conducted in laboratory of Food Science \& Technology and RFRAC, Lucknow. The sample was consist of Rice bran, chickpea peel \& wheat flour.
The sampling is given below,

\begin{tabular}{|c|l|l|c|c|}
\hline Ingredient & $\begin{array}{l}\text { Sample 1 } \\
(10 \%)\end{array}$ & $\begin{array}{l}\text { Sample 2 } \\
(15 \%)\end{array}$ & $\begin{array}{l}\text { Sample 3 } \\
(20 \%)\end{array}$ & $\begin{array}{l}\text { Sample } \\
\text { (control) }\end{array}$ \\
\hline T1 & $10 \mathrm{gm}$ & $10 \mathrm{gm}$ & $15 \mathrm{gm}$ & $100 \mathrm{gm}$ \\
\hline $\mathrm{T} 2$ & $10 \mathrm{gm}$ & $20 \mathrm{gm}$ & $20 \mathrm{gm}$ & - \\
\hline $\mathrm{T} 3$ & $80 \mathrm{gm}$ & $70 \mathrm{gm}$ & $65 \mathrm{gm}$ & - \\
\hline
\end{tabular}

Where, T1= Rice Bran, T2=.Chickpea Peel, T3= Wheat Flour

Preparation of therapeutic flour blend with Rice bran, chickpea peel, wheat flour

Tools- Rice bran, chickpea peel, and whole wheat, Weighing machine, Meeling machine, Container, etc

\section{Technique}

The develop therapeutic flour was developed using different ratio, of Rice Bran, Chickpea Peel \& Wheat Flour.Rice Bran, Chickpea Peel \& Wheat were taken for nutritional enrichment of Therapeutic flour. Rice Bran were separated from the whole rice, washed thoroughly and drained. Wheat were washed and tops as well as bran were removed and drained. So immediately food processor. The preparation of three different variation of one flour product for experiment by Rice bran, chickpea peel and whole wheat flour combination. 


\section{International Journal of Science and Research (IJSR) \\ ISSN (Online): 2319-7064}

Index Copernicus Value (2016): 79.57 | Impact Factor (2015): 6.391

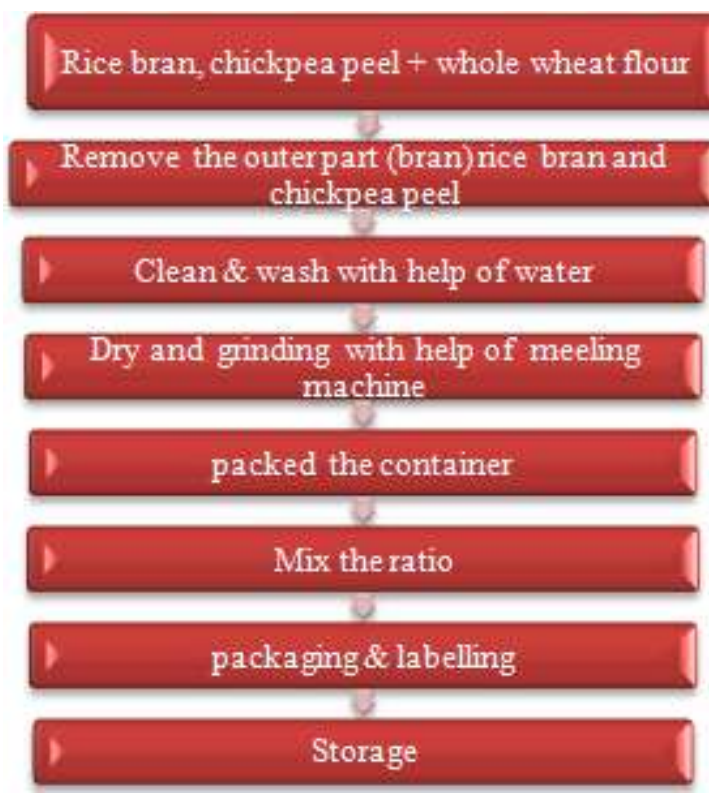

Figure: Flow chart for the manufacturing of therapeutic flour.

Preparation of Experiment

This phase mainly deals with the preparation of three different variation of one flour product for experiment by Rice bran, chickpea peel and whole wheat flour combinations.

Tools- Rice bran, chickpea peel, and whole wheat, Weighing machine, Meeling machine, Container, etc.

\section{Product Development}

Treatment for the preparation of therapeutic flour chilla $\mathbf{T}_{1}$. Whole wheat flour $+5 \%$ Rice bran $+5 \%$ chickpea peel $\mathbf{T}_{2}$ - Whole wheat flour $+5 \%$ Rice bran +10 chickpea peel $\mathbf{T}_{3}$ - Whole wheat flour (Control)

Chilla making procedure-

Flow chart

The preparation of three different variation of one flour product for experiment by Rice bran, chickpea peel and whole wheat flour combination.

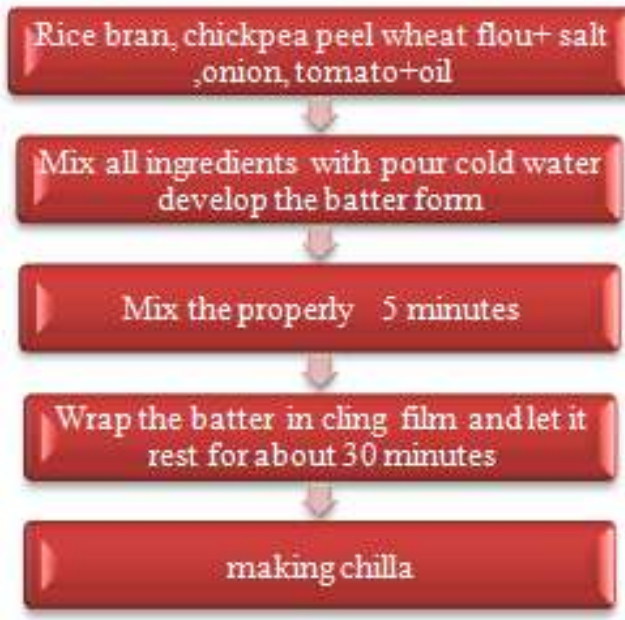

Figure: Flow chart of making chilla

\section{Result}

\section{Sensory evaluation}

Sensory evaluation of therapeutic flour was done by the 5 member panellist.

Ratio of ingredients for three samples are taken in different ways-

Table: Ratio of Ingredients

\begin{tabular}{|c|c|c|}
\hline Treatments & Sample preparation & $\begin{array}{c}\text { Ratio of } \\
\text { Ingredients }\end{array}$ \\
\hline $\mathrm{T}_{1}$ & $\begin{array}{c}\text { Rice bran + chickpea peel + } \\
\text { whole wheat flour }\end{array}$ & $10: 10: 80$ \\
\hline $\mathrm{T}_{2}$ & $\begin{array}{c}\text { Rice bran + chickpea peel + } \\
\text { whole wheat flour }\end{array}$ & $5: 10: 85$ \\
\hline $\mathrm{T} 3$ & $\begin{array}{c}\text { Rice bran + chickpea peel + } \\
\text { whole wheat flour }\end{array}$ & $20: 30: 50$ \\
\hline
\end{tabular}

\section{Parameter 1- Flavour and Taste}

Table- Individual markings for flavour and taste

\begin{tabular}{|c|c|c|c|}
\hline Members & T1 & T2 & T3 \\
\hline 1 & 9 & 7 & 5 \\
\hline 2 & 8 & 6 & 6 \\
\hline 3 & 8 & 6 & 5 \\
\hline 4 & 7 & 6 & 6 \\
\hline 5 & 8 & 6 & 6 \\
\hline Total & 40 & 31 & 28 \\
\hline
\end{tabular}

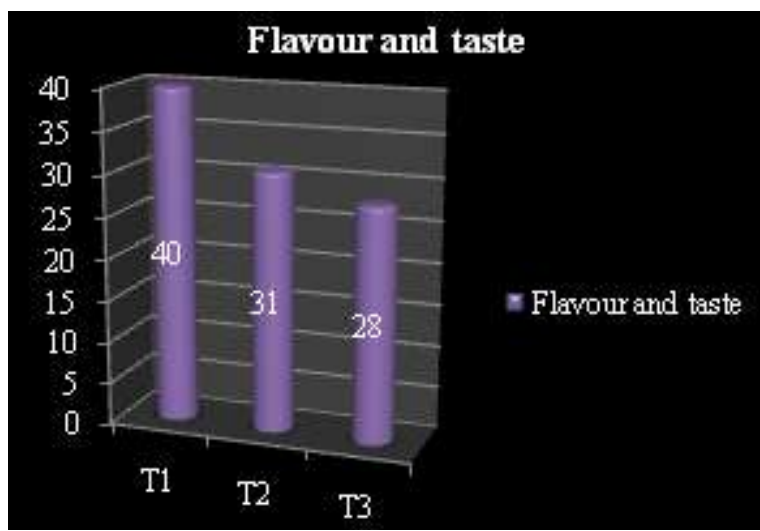

Figure: Graphical Representation- Flavour and Taste

From the above graph it shows that the sample T1 is most accepted among the panalist members and it get highest scoring, then after sample T2 and sample T3 respectively.

Parameter 2: Body and Texture

Table: Individual Markings- Body and Texture

\begin{tabular}{|c|c|c|c|}
\hline Members & T1 & T2 & T3 \\
\hline 1 & 7 & 7 & 6 \\
\hline 2 & 7 & 6 & 6 \\
\hline 3 & 7 & 6 & 6 \\
\hline 4 & 8 & 6 & 6 \\
\hline 5 & 8 & 5 & 5 \\
\hline Total & 37 & 30 & 29 \\
\hline
\end{tabular}

Volume 6 Issue 12, December 2017

www.ijsr.net 


\section{International Journal of Science and Research (IJSR) \\ ISSN (Online): 2319-7064}

Index Copernicus Value (2016): 79.57 | Impact Factor (2015): 6.391

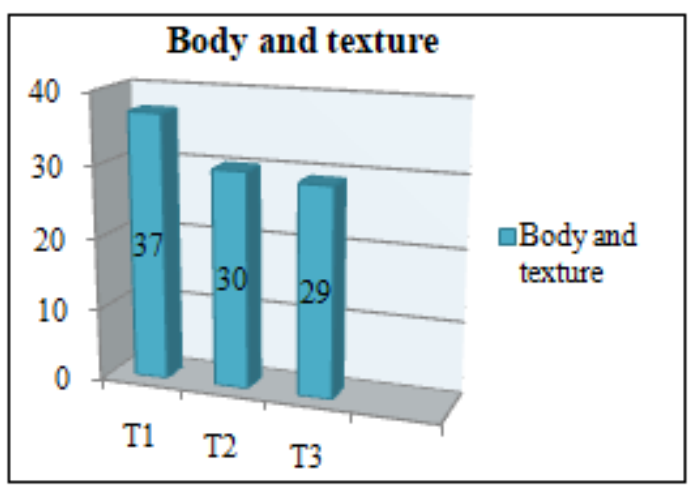

Figure: Graphical Representation- Body and texture

From the above graph it shows that the sample T1 is most accepted among the panalist members and it get highest scoring, then after sample $\mathrm{T} 2$ and sample $\mathrm{T} 3$ respectively

Parameter 3: Colour and Appearance

Table: Individual markings- Colour and Appearance

\begin{tabular}{|c|c|c|c|}
\hline Members & T1 & T2 & T3 \\
\hline 1 & 7 & 7 & 5 \\
\hline 2 & 8 & 7 & 8 \\
\hline 3 & 7 & 7 & 7 \\
\hline 4 & 7 & 6 & 7 \\
\hline 5 & 8 & 7 & 6 \\
\hline Total & 37 & 34 & 33 \\
\hline
\end{tabular}

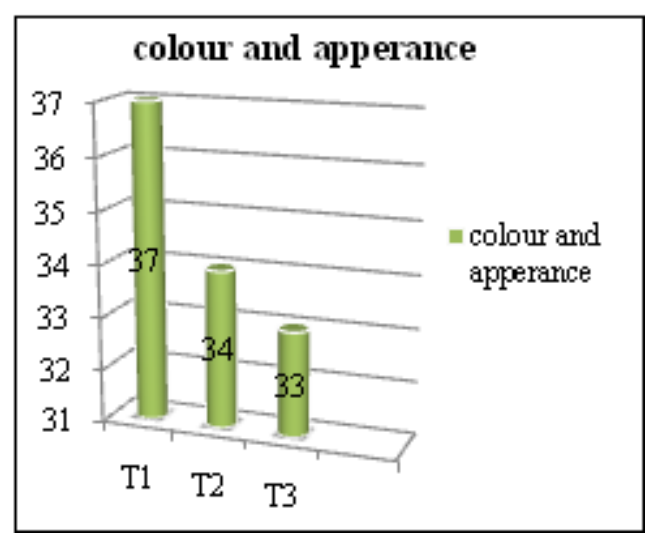

Figure 28: Graphical Representation- Colour and apperance

From the above graph it shows that the sample T1 is most accepted in terms of colour and appearance among the sensory panellist members and it gets highest scoring, then after sample $\mathrm{T} 1$ and $\mathrm{T} 2$ respectively

\section{Parameter4- Overall Acceptability}

Table: Individual Markings- Overall Acceptability

\begin{tabular}{|c|c|c|c|}
\hline Members & T1 & T2 & T3 \\
\hline 1 & 8 & 7 & 5 \\
\hline 2 & 8 & 8 & 7 \\
\hline 3 & 8 & 8 & 8 \\
\hline 4 & 7 & 5 & 5 \\
\hline 5 & 8 & 7 & 6 \\
\hline Total & 39 & 35 & 31 \\
\hline
\end{tabular}

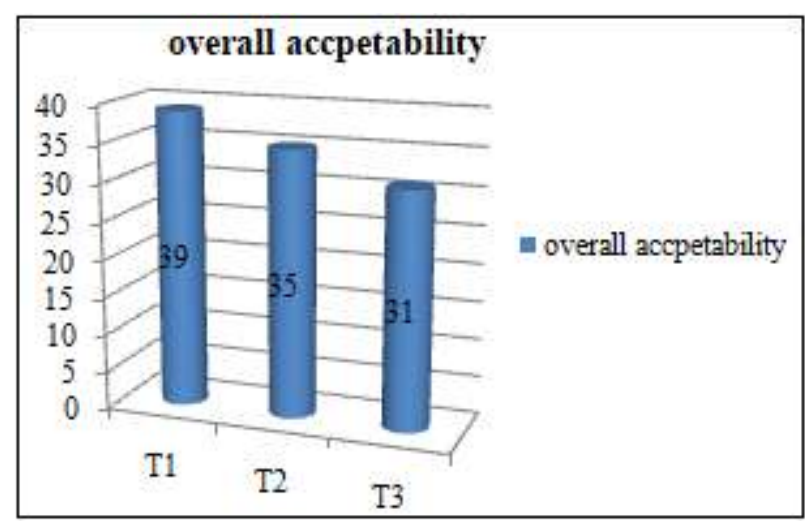

Figure: Graphical Representation- Overall acceptability

From the above graph it shows that the sample T1 is most accepted overall among the sensory panellist members and it gets highest scoring, then after sample T2 and T3 respectively.

The overall quality of therapeutic flour with $10 \%$ Rice bran \& $10 \%$ chickpea peel \& $80 \%$ wheat flour was the most acceptable in all the parameters of quality.

\section{Parameter 5 -Overall Calculation}

Overall calculation are done to know most acceptability of the product in all terms of quality by sensory evaluation scoring given by the panellist members, in this all scoring of texture, colour, flavour and taste are calculated in the table, by this we get do statistical analysis and obtained standard deviation, average and other calculations.

Table: Overall Calculation

\begin{tabular}{|c|c|c|c|}
\hline Parameters & T1 & T2 & T3 \\
\hline 1 & 40 & 31 & 28 \\
\hline 2 & 37 & 30 & 29 \\
\hline 3 & 37 & 34 & 33 \\
\hline 4 & 39 & 35 & 31 \\
\hline Total & 153 & 130 & 121 \\
\hline Average & 38.25 & 32.5 & 30.25 \\
\hline Standard Deviation & 1.5 & 2.38 & 2.21 \\
\hline
\end{tabular}

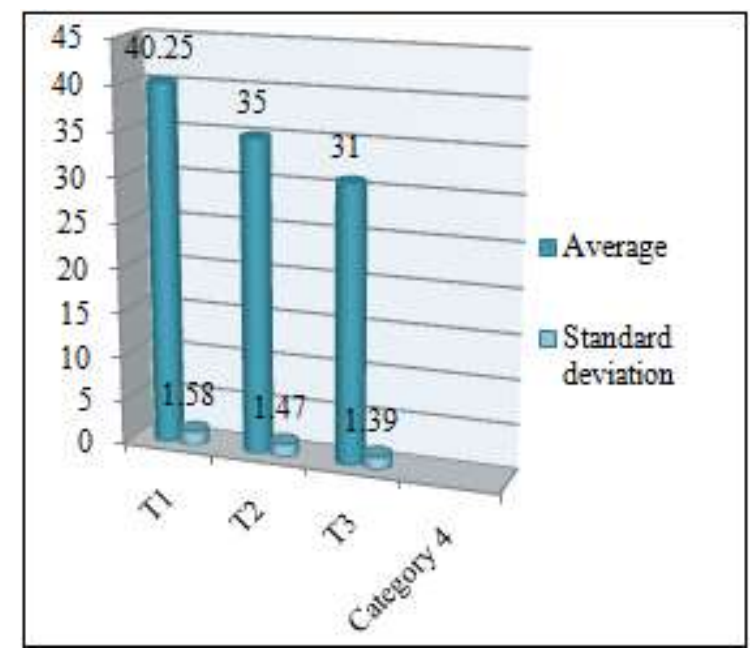

Figure: Graphical Representation- Overall calculation

In this table of overall calculation we got the average of T1, $\mathrm{T} 2$ and $\mathrm{T} 3$ as $1.5,2 . .38$ and $2 . .21$ respectively. 


\section{International Journal of Science and Research (IJSR) \\ ISSN (Online): 2319-7064}

Index Copernicus Value (2016): 79.57 | Impact Factor (2015): 6.391

Sample T1 with highest average and low standard deviation is most accepted statically, hence T1 is most accepted.

\section{References}

[1] Renu Sharma et al. Int. Journal of Engineering Research and Applications www.ijera.com ISSN : 2248-9622, Vol. 5, Issue 5, ( Part -2) May 2015, pp.107-112

[2] Jukanti, A.K., Gaur, P.M., Gowda, C.L.L. and Chibbar, R.N., 2012.Nutritional quality and health benefits of chickpea (Cicer arietinum L.): a review. British Journal of Nutrition, 108(S1), pp.S11-S26.

[3] Salehifar, M. and Fadaei, V., 2011. Comparison of some functional properties and chemical constituents of dietary fibers of Iranian rice bran extracted by chemical and enzymatic methods. African Journal of Biotechnology, 10(80), pp.18528-18531.

[4] R. Sivashankar, S. A. Srinivasan, S. Shankar, R. Rajasekar, R. Naveen Kumar, P. Sathish Kumar. "Review article on wheat flour/wheat bran/wheat husk based bio-composites," International Journal of Scientific and Research Publications, Vol.4, No. 4, 2014.

Volume 6 Issue 12, December 2017

www.ijsr.net 